\title{
PREPOSICIÓN Y CONJUNCIÓN COMO CLASES DE PALABRAS EN ESPAÑOL
}

\author{
José Manuel González Calvo
}

\begin{abstract}
The author of this article defends the technical need to speak Spanish syntax of two kinds of linking words, by their difference in function: the subordinating and coordinante. The fall in subordinating conjunctions and prepositions (the traditional subordination). The term used to name coordinante traditional coordinating conjunctions.

Keywords: linking words; coordinante; subordinating; preposition; conjunction.

Resumen: El autor de este artículo defiende la necesidad técnica de hablar en sintaxis española de dos clases de palabras de enlace, por su diferencia de función: el subordinante y el coordinante. Los subordinantes se clasifican en preposiciones y conjunciones (las tradicionales de subordinación). El término coordinante sirve para nombrar las tradicionales conjunciones de coordinación.

Palabras claves: palabras enlace; coordinante; subordinante; preposición; conjunción.
\end{abstract}

1.1. El objetivo de este trabajo se centra en la caracterización de preposición y conjunción como clases de palabras en español. Cada lengua ha de establecer su sistema de clases de palabras, y a partir de ahí definir o caracterizar cada categoría o clase por las diferencias formales y funcionales que mantenga con el resto de clases de palabras, sobre todo con las más afines. Si sustantivo y adjetivo tienen en común ser las dos categorías básicas de la macrocategoría del nombre, habrán de ser criterios morfológicos y sintácticos los que puedan probar o no que estamos en español ante dos categorías y no ante dos subclases de una misma categoría. De manera parecida, preposición y conjunción pertenecen a la macrocategoría del llamado relacionante (palabras de enlace), y el análisis de su manera funcional de enlazar permitirá caracterizarlas como dos categorías afines pero diferentes. Ello conduce en este trabajo a proponer las denominaciones de subordinante y coordinante como nombres más adecuados para el estudio de las dos clases de palabras de enlace en español.

1.2. Los sintagmas, consten de una o más palabras, se relacionan en la estructura interna de la oración de diversas maneras. Una de ellas es mediante palabras de enlace, cuyo cometido sintáctico consiste en actuar como nexos indicadores de dependencia o de equifuncionalidad sintácticas entre los segmentos que conectan. Estas palabras no cumplen las funciones sintácticas reconocidas de sujeto, predicado, complemento... Su actividad 
sintáctica no suele ser considerada como función, lo que obliga a distinguir entre función sintáctica y papel sintáctico. Toda función sintáctica cumple un papel sintáctico dentro de la oración, pero no todo cometido sintáctico se acepta como función sintáctica. Sucede esto con preposiciones y conjunciones, con los determinantes del sustantivo (especialmente el artículo en español) y con los determinantes de adjetivos y de adverbios (Muy despistado. Tan lejos). Como elementos de enlace, las preposiciones y conjunciones en español son palabras átonas, invariables morfológicamente, sin autonomía sintáctica (no pueden formar sintagma por sí mismas) salvo en casos especiales, y con unos contenidos tan genéricos dentro de su labor de conexión que para algunas de ellas se reducen al simple valor semántico y sintáctico de señalar que un elemento depende de otro o que los elementos vinculados desempeñan la misma función sintáctica (sin precisar cuál es esa función). No es de extrañar que, por su atonicidad y por su valor de relación, se haya podido pensar y plantear que poseen más categoría de morfemas que de palabras. Por mi parte, he sostenido, y sigo manteniendo, que artículo, preposiciones y conjunciones en español son palabras, no morfemas (González Calvo 2000: 309-329). Considero que la palabra es una unidad gramatical en nuestra lengua, sin negar por ello los evidentes casos limítrofes con otras unidades o magnitudes gramaticales (morfema por un extremo y grupo sintagmático por el otro). He definido la palabra en español como el signo lingüístico (significante + significado o contenido) mínimo con libertad o independencia de significante (siempre es posible introducir otra palabra o secuencia entre dos palabras contiguas), que cumple un papel sintáctico en el sintagma, o entre sintagmas. Se entiende que si un sintagma, como esquema sintáctico de combinación de palabras, consta de una única palabra, esa palabra actúa en la oración como sintagma. Si en español una sílaba (esquema mínimo de combinación fónica) puede estar constituida por un único alófono de un fonema (necesariamente vocálico en español, no así en checo, por ejemplo), también un sintagma puede configurarse con un único significante de una palabra. No por ello se confunde fonema con sílaba, ni hay por qué confundir tampoco palabra con sintagma. En los estudios gramaticales del español, hay dos posturas al analizar el valor sintagmático de preposiciones y conjunciones: a) No funcionan como núcleo de sintagma; b) son el núcleo de los respectivos sintagmas prepositivos y conjuntivos. Los estudios generativistas, o afines, sobre gramática española argumentan a favor de la segunda postura. Los funcionalistas, en cambio, rechazan con firmeza ese análisis. Pienso que no procede hablar en español de sintagmas preposicionales (SPrep), sino de sintagmas nominales precedidos por una preposición que indica su carácter de elemento regido. Más complicado sería hablar de sintagmas conjuntivos (SConj), pues el comportamiento funcional de las conjunciones de subordinación frente a las de coordinación es muy distinto. Volveré sobre esto.

2.1. Es sabido que Platón distinguió dos grandes partes de la oración, que se referían al sujeto y al predicado: onóma y rema. No se trataba exactamente de clases de palabras, sino de auténticas partes de la oración entendida como sujeto (onóma) + predicado (rema). Aristóteles añadió a esas dos partes las partículas (síndesmoi) o elementos de enlace. Estos tampoco eran clases de palabras tal como hoy las entendemos. Para las clases de palabras, la clasificación más antigua de la que tenemos conocimiento es la de Dionisio de Tracia (siglo IV a.C.). Distinguió ocho clases, entre las que se encuentran la preposición y la conjunción. En la época romana tardía, Prisciano sigue con las ocho 
clases, y entre ellas están la preposición y la conjunción. En la clasificación de Dionisio figura el artículo (en griego hay artículo), no así en la de Prisciano (el latín no tiene artículo, como tampoco lo tiene el checo, por ejemplo), que tuvo que hacer de la interjección una clase de palabra para que también el latín tuviera ocho (Černý 2008: 20). Preposición y conjunción como clases de palabras han llegado hasta nuestros días en los tratados gramaticales de la lengua española. Haré un pequeño repaso selectivo de manuales gramaticales desde la aparición del Esbozo de una nueva gramática de la lengua española (RAE 1973) hasta nuestros días.

2.2.1. El Esbozo académico (RAE 1973: 434-443) dedica un apartado específico a la preposición como clase de palabra, no así a la conjunción. Trata las conjunciones en el apartado titulado De la oración compuesta en general (RAE 1973: 500-503). Es aquí donde se dice que las preposiciones y las conjunciones son nexos oracionales, y se señala que suele definirse la preposición como palabra que relaciona elementos de la oración simple, mientras que a la conjunción corresponde el enlace de oraciones dentro del período. Se comenta que estas definiciones son exactas en general, pero al tratar de aplicarlas en sus límites extremos aparecen a veces zonas borrosas. Pone como ejemplo el uso conjuntivo de las preposición con: Pedro con su hijo fue (o fueron) a visitarme. Por otra parte, se dice que las conjunciones de coordinación enlazan también elementos de la oración simple. Entiendo que no resulta fácil pretender caracterizar la conjunción con un criterio sintáctico funcional cuando subordinar y coordinar son actividades sintácticas contrapuestas. La preposición no plantea este escollo, pues siempre relaciona por subordinación. Dice el Esbozo (RAE 1973: 434-435) que muchos complementos se enlazan en español por medio de una preposición. La define provisionalmente como palabra invariable que enlaza «un elemento sintáctico cualquiera con un complemento sustantivo». El elemento sintáctico de donde parte la relación es el inicial, y «el concepto sustantivo es terminal, cualquiera que sea el orden que guarden entre sí dentro de la oración». Esto es así porque precede siempre a su término (se usan siempre en proclisis), formando con él una unidad sintáctica y fonética, incluso en los casos de hipérbaton más extremo. El término puede ir precedido de otra preposición; en esta circunstancia, la primera establece la relación entre el elemento inicial y el todo que forman la segunda preposición y su término: De entre unas breñas; Desde por la mañana. Por el solo hecho de ser término de una preposición, se sustantivan todos los vocablos (pronombres, adverbios pronominales) y expresiones (oraciones subordinadas) que se sitúen como términos: El temor de que llegasen tarde. Tras estas y otra explicaciones, el manual académico (RAE 1973: 438) vuelve a la definición: «Las preposiciones son partículas proclíticas (salvo según) que encabezan un complemento nominal de otra palabra y lo subordinan a ella». En todas las gramáticas que repasaremos se advertirá, como en el Esbozo, que la caracterización de la preposición ofrece pocas dificultades. Sin embargo, no se sabe muy bien qué hacer con la conjunción como clase de palabra.

2.2.2. Si se confunden las clases de palabras con las clases de funciones sintácticas, y oración con sintagma verbal (SV), cualquier definición de una clase de palabra resulta comprometedora, insatisfactoria e irresoluble. La gramática de Alcina-Blecua (1975: 824-841) repasa la teoría de la gramatical académica, así como la de Andrés Bello, suficientemente conocidas, sobre preposición y conjunción, y no propone nada nuevo. Manuales más recientes van precisando algunos puntos. Para Alarcos Llorach (1994: 214-215), preposicio- 
nes y conjunciones son unidades de relación que aparecen en los enunciados junto con las palabras autónomas (verbos, sustantivos, adjetivos y adverbios), a las que presuponen y a las que marcan las relaciones que mantienen entre ellas. Las unidades de relación, como unidades dependientes, son unidades carentes de autonomía, cuyos significantes en general son átonos y forman con la palabra a la que preceden una solo entidad fónica. Las preposiciones incrementan a los sustantivos, adjetivos o adverbios como índices explícitos de las funciones que tales palabras cumplen bien en la oración, bien en el grupo unitario nominal: Habla de la guerra (objeto preposicional del verbo); El recuerdo de la guerra (adyacente del sustantivo recuerdo). La preposición solo sirve como índice del papel que desempeña el segmento en que está integrada, por lo que es evidente que por sí sola no cumple función alguna especial dentro del enunciado. Las preposiciones, además de ser índices funcionales, comportan un valor léxico. Con el término conjunciones se reúnen en una misma categoría elementos que permiten incluir oraciones dentro de un mismo enunciado. Se distinguen las de coordinación y las de subordinación. Considerando la función que desempeñan, las de coordinación son conectores y las de subordinación son transpositores. Los transpositores degradan (al igual que los relativos) la oración en la que se insertan y la transponen funcionalmente a una unidad de rango inferior que cumple algunas de las funciones propias del sustantivo, del adjetivo o del adverbio, «esto es, la de ser adyacentes subordinados a un núcleo verbal, o en su caso, sustantivo». En este sentido se asemejan a las preposiciones, por cuanto estas señalan también la función del segmento que encabezan. Por mi parte, creo que esta teoría de la transposición no resuelve las insuficiencias de caracterización de la conjunción como clase de palabra. Preposiciones y conjunciones de subordinación subordinan un elemento a otro. Las conjunciones de coordinación relacionan elementos de igual función, no hacen que uno dependa de otro. Si se distinguiera con claridad entre transpositores (preposiciones y conjunciones de subordinación) y conectores (conjunciones de coordinación) tendríamos dentro de la macrocategoría de las unidades de relación dos clases de palabras más claramente delimitadas y no confundidas en una de sus partes. Aun así, no soy partidario de la teoría de la transposición.

2.2.3. Las gramáticas modernas del español siguen insistiendo en que preposiciones y conjunciones tienen estas características comunes: son palabras átonas (excepto según), invariables, constituyen clases cerradas, nunca pueden actuar con autonomía sintáctica, y relacionan unos elementos sintácticos autónomos con otros sirviendo de enlace entre ellos. Cuando aparecen en enunciados de carácter metalingüístico, y también en algunas expresiones coloquiales, se observan usos autónomos: ¿Por? ¿Y? En los usos metalingüísticos actúan como sustantivos: «Por es una preposición». Las diferencias entre esas dos clases de palabras son funcionales. La preposición estable siempre una relación de subordinación o dependencia; se une a una palabra o grupo de palabras con las que forma una construcción preposicional (grupo o sintagma preposicional) que complementa a una palabra anterior (verbo, sustantivo, adjetivo, adverbio, pronombre). El término de la preposición no es, generalmente, una secuencia con verbo en forma personal (sí con verbo en forma no personal). Las conjunciones pueden ser de coordinación (relacionan elementos del mismo nivel sintáctico) y de subordinación. La diferencia entre preposiciones por una parte y conjunciones subordinantes por otra consiste en que estas últimas subordinan oraciones con verbo en forma personal. Las preposiciones necesitan 
unirse a las conjunciones que o si para subordinar secuencias con verbo en forma personal. Algunas preposiciones se unen también a pronombres o adverbios relativos para introducir oraciones relativas: para quienes, para cuando. En suma, las conjunciones de subordinación relacionan una palabra (o una secuencia oracional) con una oración dependiente o subordinada: unen siempre una oración subordinada a una palabra o a otra oración (Gómez Torrego 2007: 218-219 y 230-231). El manual de Marcos Marín (2002: 275) habla de elementos de relación, que incluyen unidades heterogéneas caracterizadas por los rasgos ya reseñados. Se recuerda que estos elementos han recibido diversos nombres en las gramáticas: partículas, nexos, enlaces, unidades de relación... Además de las preposiciones y conjunciones, desempeñan esta función de servir de elementos de relación ciertos pronombres y adverbios (los relativos). Por lo expuesto hasta aquí, se observa que Alarcos y Gómez Torrego entienden, como casi todos los gramáticos en la actualidad, que preposiciones y conjunciones no están totalmente vacías de significado. Las hay con significado propio, otras con significado deducido del contexto, y otras sin significado léxico alguno aunque con contenido gramatical (por ejemplo, las preposiciones en los complementos de régimen). En el manual de Marcos Marín (2002: 276) se dice que los elementos de relación tienen un significado no designativo, sino nocional situacional u orientador. Se ordenan por el tipo de relación que establecen. Se cita a Ana $\mathrm{M}^{\mathrm{a}}$ Barrenechea, que los clasifica de manera diferente a lo que ha sido norma en la tradición gramatical: coordinantes, subordinantes y relacionantes. Estos últimos son signos con doble función: subordinación e inclusión más funciones de sustantivo, adjetivo o adverbio. Después de esta cita, se dice que, no obstante lo anterior, la clasificación tradicional en preposiciones y conjunciones tiene ventajas que la hacen preferible a otras. Por ello, se afirma que no parece conveniente englobar las preposiciones y parte de las conjunciones (las de subordinación) en un único grupo de subordinantes, aunque funcionalmente desempeñen papeles semejantes (Marcos Marín 2002: 292). Černý (2008: 145-151) sostiene que la diferencia entre las conjunciones coordinantes y subordinantes es tan grande como la que hay entre las oraciones coordinadas y las subordinadas, y por eso las trata por separado. Emplea el término enlaces (los enlaces) para englobar las preposiciones y las conjunciones.

2.2.4. Pavón (1999: 622-623) opina que podemos establecer una estrecha relación entre conjunciones subordinantes y preposiciones. El criterio de la categoría gramatical del término no permite establecer una distinción clara entre unas y otras. Sin embargo, el criterio de la coordinación frente a la subordinación sí nos lleva a establecer una distinción más nítida, pero entre preposiciones y conjunciones subordinantes, por una parte, y conjunciones coordinantes, por otra. Se rompe así la unidad tradicional de la categoría conjunción. Pavón (1999: 567-568) titula su trabajo: «Clases de partículas: preposición, conjunción y adverbio». Dice que esas tres categorías presentan una serie de características comunes, entre ellas la de establecer relaciones entre oraciones o entre partes de la oración. El adverbio no introduce un segundo término de relación, pero, afirma esta autora, encierra en sí el valor del elemento de relación. Creo que preposiciones y conjunciones de subordinación pertenecen a una misma clase de palabras, y que dentro de ella están en distribución complementaria. Pero no puedo estar de acuerdo, siempre con el respeto debido ante opiniones distintas, con la inclusión del adverbio entre las partículas de relación o enlaces. La Nueva gramática de la lengua española (NGLE), de la Real Aca- 
demia Española y Asociación de Academias de la Lengua Española (RAE-AALE 2010: 575), parece que relaciona también el adverbio con los elementos de relación. El capítulo 29 lo dedica a la preposición, el 30 al adverbio y el 31 a la conjunción (deteniéndose en el estudio de las construcciones coordinadas). Dice que el adverbio se caracteriza por dos factores: uno morfológico, la ausencia de flexión, y otro sintáctico, la capacidad de establecer una relación de modificación con grupos sintácticos correspondientes a distintas categorías. Los adverbios modifican a los verbos, a los adjetivos y también a otros adverbios. Además, ciertos adverbios pueden incidir sobre grupos nominales, pronominales o preposicionales, así como modificar oraciones. Considero que el adverbio en español, funcionalmente, y no solo eso, es una clase de palabra muy diferente de preposición y conjunción. Dejando a un lado estas consideraciones, el estudio que la NGLE hace de preposiciones y conjunciones es muy detallado, puesto al día y con apreciaciones que suponen un gran avance respecto a la tradición gramatical académica. Pero las definiciones no presentan nada nuevo. Dice que las preposiciones son palabras invariables y por lo general átonas que se caracterizan por introducir un complemento que en la tradición gramatical hispánica se denomina término. La preposición y su término forman en conjunto un grupo preposicional o prepositivo. Las preposiciones forman una clase gramatical cerrada, aunque el gran número de locuciones preposicionales existentes alarga de manera considerable ese paradigma, sin convertirlo en abierto. Dichas locuciones constan de varias palabras que adquieren conjuntamente el sentido y el funcionamiento de las preposiciones: a falta de, por encima de, en aras de... Las gramáticas citadas antes hablan asimismo de las locuciones preposicionales, pero no coinciden en los inventarios de preposiciones y locuciones. Para la NGLE (RAE-AALE 2010: 557-574), el significado de las preposiciones es abstracto y casi siempre relacional. La distinción entre preposiciones de contenido gramatical o funcional y de contenido léxico se considera gradual, ya que los procesos de gramaticalización son asimismo graduales: no es posible asignar a de un contenido léxico particular, frente a sin, que tiene más contenido léxico. La caracterización y la clasificación (en coordinantes y subordinantes) que la NGLE (RAE-AALE 2010: 603-622) hace de las conjunciones tampoco aporta novedades, por lo que excuso andar con exposiciones. Sí habla de las locuciones conjuntivas y de las dificultades de clasificar las conjunciones subordinantes. Hay una cuestión que extraña en esta gramática y en las ya citadas. ¿Por qué, si se habla de preposición y su término, no se insiste, paralelamente, en la conjunción subordinante y su término? La conjunción subordinante, como la preposición, siempre se desplaza con su término. Las conjunciones coordinantes no tienen funcionalmente término, por lo que no se desplazan con él: Fueron y les atendieron - *Y les atendieron fueron.

3.1. En todo lo anteriormente expuesto, aparecen más semejanzas que diferencias a la hora de definir preposición y conjunción como clases de palabras en español. La distinción de Alarcos, dentro de la conjunción, entre transpositores y conectores se aparta de nuestra tradición gramatical. La opinión de Marcos Marín, que no estima conveniente englobar en un único grupo de subordinantes a preposiciones y conjunciones de subordinación, contrasta con la postura de Pavón, y en alguna medida con la de Černý. Pienso que técnicamente no procede hablar de preposición y conjunción, aunque acaso siga siendo útil en la enseñanza mantener, de manera práctica, esa distinción con esos nombres, hasta que se asiente, si se asienta, otra manera de nombrar y subclasificar las palabras de relación. Los enlaces o relacionantes, como macrocategoría aglutinadora, acoge al 
menos dos clases de palabras: los subordinantes y los coordinantes. Son criterios funcionales los que permiten establecer esta distinción, y son criterios distribucionales y semánticos los que servirán para fijar subclasificaciones. Es preciso que exponga brevemente lo que entiendo por sintagma verbal y por oración para poder argumentar con coherencia. Una oración, como entidad constituida, supera los límites de la sintaxis. Toda oración, como unidad paradigmática, tiene una estructura interna, que es material sintáctico, y una actividad externa de tipo enunciativo-discursivo. Toda oración se relaciona con otra sin que entre ellas pueda existir relación hipotáctica (dependencia formal). Entiendo el enunciado como la unidad sintagmática enunciativa-discursiva correspondiente. Es el esquema mínimo de combinación de oraciones, aunque un enunciado puede constar de una única oración (en sintaxis un sintagma puede constar de una sola palabra). La estructura interna de una oración puede estar cumplida por un único sintagma simple (verbal, sustantivo, adjetival, adverbial). En español es frecuente que una oración conste de un único sintagma verbal más simple o más complejo, que es lo que tradicionalmente se entiende como oración simple. Este hecho no puede conducirnos a identificar oración y sintagma verbal. Mañana lloverá mucho es una oración que consta de un SV complejo. El parte meteorológico ha dicho esta tarde que mañana lloverá mucho es una oración que posee dos sintagmas verbales complejos, uno regente (donde se halla el verbo núcleo de la oración, además de ser el núcleo de su SV regente) y otro regido (cuyo verbo es solo núcleo de su SV subordinado). No se debe hablar de oración principal y oración subordinada, pues no hay dos oraciones. Estamos ante una oración con SV regente y SV regido. Así pues, las conjunciones de subordinación no subordinan oraciones, sino sintagmas verbales con verbo en forma personal. No cabe subordinar oraciones, sino sintagmas. Las preposiciones subordinan otros tipos de sintagmas que no sean los verbales en forma personal. Preposiciones y conjunciones subordinantes subordinan elementos propios de la estructura sintagmática de la oración. Conjunciones subordinantes y preposiciones cumplen el mismo papel sintáctico, y se distinguen porque lo cumplen en distribución complementaria, como se habrá observado. Son subordinantes en distribución complementaria. Morfológica y funcionalmente constituyen una única clase de palabras. Los coordinantes (llamados conjunciones de coordinación) conectan elementos con relación paratáctica (nunca hipotáctica): sintagmas en la estructura interna de la oración (material sintáctico) y oraciones en el enunciado compuesto de dos o más oraciones por coordinación. En suma, el criterio de distribución complementaria distingue, dentro de los subordinantes, preposiciones y conjunciones, a condición de que no se hable de conjunciones de coordinación, sino simplemente de coordinantes. Los criterios semántico y combinatorio permitirán intentar analizar tipos de subordinantes (prepositivos y conjuntivos) y de coordinantes (copulativos, disyuntivos, adversativos...). En este sentido son muy útiles las gramáticas citadas.

3.2.1. En la definición de palabra expuesta más arriba se decía que la palabra cumple siempre un papel sintáctico en el sintagma (o constituye por sí misma sintagma), o entre sintagmas. En esta segunda parte se centra el oficio sintáctico de las preposiciones y conjunciones tradicionales. Sin embargo, al aislar los coordinantes como clase de palabra en español, y al afirmar que la oración y el enunciado superan los límites de la sintaxis, por coherencia metodológica es necesario distinguir tres tipos de palabras (y locuciones) de enlace teniendo en cuenta la parte y el nivel gramaticales en los que intervienen (pienso 
que la textología es una parte de la gramática de una lengua, y es distinta de la parte sintáctica): partes sintáctica y textual, y dentro de la parte textual distingo el nivel enunciativo (dos o más oraciones en un enunciado) y el supraenunciativo (varios enunciados en un párrafo, etc.). Explico ahora la propuesta.

A) En sintaxis tenemos dos clases de palabras: el subordinante y el coordinante. Solo en la parte sintáctica de la gramática podemos fijar la oposición funcional de subordinar frente a la de coordinar. La primera clasificación de los subordinantes sería, por lo ya expuesto, en preposiciones y conjunciones.

B) En la parte textual tendríamos los conectores o marcadores discursivos. Por el nivel de actuación, la primera clasificación de estas palabras (y locuciones) de enlace sería en conectores enunciativos y conectores supraenunciativos. En ninguno de estos dos niveles textuales entra la oposición funcional de subordinar / coordinar: solo existen relaciones paratácticas, nunca hipotácticas, entre los elementos conectados. El nivel textual enunciativo constituye la intersección entre las partes sintáctica y textual de la gramática de una lengua, y se observa que los significantes de coordinantes y de conectores enunciativos coinciden en buena medida. Sin embargo, el enlace de enunciados para formar párrafos, y la conexión de párrafos en partes más amplias del texto, corre a cargo en español de una variedad de palabras y locuciones entre las que no están excluidos los conectores enunciativos. El carácter de los enlaces discursivos supraenunciativos sobrepasa con creces las posibilidades que se describen para los coordinantes sintácticos y los conectores enunciativos. Dice la NGLE (RAE-AALE 2010: 595) que los conectores discursivos no forman una clase sintáctica de palabras en el sentido en que lo son el verbo, la conjunción o el adverbio, «ya que constituyen un grupo establecido con criterios textuales». La mayor parte de los conectores discursivos, sigue la NGLE, son adverbios (encima, además), pero algunos son conjunciones coordinantes o subordinantes, incluso preposiciones, o bien locuciones formadas con todas estas clases de palabras. No puedo entrar en más detalles.

3.2.2. Dijimos que los subordinantes tienen término, no así los coordinantes. Por ello se habla en sintaxis de SPrep y, en menor medida, de SConj (conjunción de subordinación). Ahora bien, y como ya expusimos, solo los autores que sostienen que la preposición (el subordinante) es el núcleo del SPrep manifiestan coherencia al hablar de sintagma preposicional, pues cada tipo de sintagma se nombra por la categoría léxica que actúa como núcleo. Quienes consideran que el SPrep es un SN (el núcleo es el sustantivo) subordinado, y que la preposición es el índice de la subordinación, creo que deberían hablar, y así lo hago yo, de SN en subordinación (o SN precedido de preposición). La gramática generativa defiende la preposición como núcleo a la que sigue su término. Desde esta perspectiva, se dice que la preposición es el núcleo porque exige un complemento y además reclama también la marca de caso (Rodríguez Ramalle 2005: 449). Defiendo que la preposición no exige complemento ni reclama caso, es el complemento el que, como elemento regido, puede pedir una preposición para enlazar con su elemento regente, y una vez solicitada y otorgada, esa preposición enlaza, relaciona, y no tiene autonomía sintáctica. No es un juego de palabras. En general, los funcionalistas mantienen el nombre de SPrep, aunque entienden que la preposición no es el núcleo de ese sintagma. Gutiérrez Ordóñez (2007: 209-219) ha argumentado contra la postura de la gramática generativa, 
y concluye afirmando que conviene evitar esa visión invertida, «muy semejante a la de creer con Cándido que los ríos están hechos para pasar por debajo de los puentes».

3.2.3. La distinción dentro de las palabras de relación subordinantes entre preposición y conjunción, tiene las ventajas, entre otras, de que pueden explicarse mejor ciertas combinaciones entre subordinantes (de la misma especie o no), y de que algunas palabras pronominales puedan actuar a la vez como sustantivos o adverbios y como subordinantes. De esto tratan, como se ha visto antes, las gramáticas que hemos tenido en cuenta. Dos preposiciones pueden encabezar un complemento, matizando así la referencia: Para con todos. Se sabe que la combinación de preposiciones en español no es aleatoria o libre. No insisto en ello. Tampoco es libre la combinación de preposición y conjunción: la preposición siempre va por delante acogiendo como término a la conjunción seguida de su SV con verbo conjugado. Las locuciones prepositivas han de tener como palabra final una preposición, y las conjuntivas una conjunción. Los relativos tienen la categoría de pronombres o de adverbios, y ciertos relativos poseen además el valor sintáctico de enlace subordinante. Pueden combinarse con una preposición, que ha de preceder a su término compuesto por el relativo y su SV. Ya se han visto ejemplos. Todo esto muestra la importancia de la preposición como palabra subordinante, pues nunca una preposición forma parte del término de un relativo o de una conjunción, e incluso precede ella sola a un SV con verbo en forma no personal. Después de estas apresuradas apreciaciones, y dejando a un lado la dificultad de combinación de los coordinantes entre sí (el anglicismo y/o es algo tan torpe como decir: Fuimos allí y/pero no nos recibieron), así como la posibilidad de combinación de conectores enunciativos y supraenunciativos (y además, pero no obstante...), pasaré a la definición personal de las clases de palabras propuestas: subordinante y coordinante.

4. La macrocategoría de las palabras de relación o de enlace, llamémosla de los relacionantes, posee en sintaxis los siguientes rasgos comunes pertinentes a las dos clases de palabras: subordinante y coordinante.

a) Semánticamente, 'relacionan' los significados de los elementos que enlazan, y acomodan a ese contexto semántico el contenido más gramatical o más léxico que cada relacionante posee inherentemente.

b) Sintácticamente, relacionan, por dependencia o equifuncionalidad, los elementos que enlazan.

c) Morfológicamente, son palabras invariables, tanto en derivación como en flexión.

La falta de autonomía sintáctica es un correlato (o rasgo redundante), no totalmente inamovible, del papel sintáctico que desempeñan los relacionantes. De manera parecida, la atonicidad es otro correlato (o rasgo redundante) que en alguna ocasión no se presenta tan nítido. Otro correlato (o rasgo redundante) de los relacionantes, acorde con su naturaleza, es el de constituir paradigmas cerrados, aunque las locuciones correspondientes amplían el paradigma y lo dejan, con restricciones, un tanto abierto para admitir con el tiempo nuevas locuciones. A partir de todos estos rasgos comunes, pertinentes y no tan pertinentes (pero reales), es posible definir mejor las clases de palabras subordinante y coordinante atendiendo al conjunto mínimo de rasgos distintivos propios de cada uno. 
a) El subordinante en español es una clase de palabra que semánticamente posee el rasgo inherente de 'enlace' entre palabras o sintagmas, indicando que el significado del término que le sigue (su término) modifica el significado del elemento regente; y que sintácticamente cumple el papel de índice de dependencia o subordinación, señalando que el término que le sigue (su término) está subordinado como complemento al elemento regente.

b) El coordinante en español es una clase de palabra que semánticamente posee el rasgo inherente de 'enlace' entre palabras o sintagmas, indicando que los significados de los elementos conectados (dos o más) se complementan y condicionan (no solo por adición de significados); y que sintácticamente cumple el papel de mostrar que los elementos enlazados (dos o más) mantienen entre sí igualdad funcional, por lo que ninguno de ellos es funcionalmente su término.

Estas definiciones explican que la oposición funcional subordinar / coordinar es exclusiva de la sintaxis. En la morfología se podrán observar parecidos en los compuestos léxicos, pero solo por asociación, pues los mecanismos son muy diferentes, al menos el resultado. En la textología (o gramática del texto) ni siquiera existe parecido por asociación, porque no hay ni el más mínimo asomo de subordinación funcional entre los elementos relacionados por los conectores o marcadores discursivos. En este terreno, las reglas gramaticales de la sintaxis no sirven para ser aplicadas al texto, que tiene sus propias reglas gramaticales textuales. En los enunciados compuestos por dos o más oraciones (yuxtaposición o coordinación) tampoco puede haber subordinación sintáctica de una oración con respecto a otra. Comprendo que lo más extendido es incluir en la sintaxis la yuxtaposición y coordinación de oraciones, por lo que bastaría con añadir $y$ oraciones (no entendidas como SV) en la definición del coordinante: «posee el rasgo inherente de 'enlace' entre palabras o sintagmas y oraciones». Para la conexión de partes del texto solo hay formalmente actividad coordinadora. Podríamos hablar también aquí de coordinantes (supraenunciativos), pero acaso sea más claro e ilustrador (y está más generalizado) llamarlos marcadores o conectores. Por último, la distinción, dentro de los subordinantes, entre preposiciones y conjunciones ya ha sido explicada; en tal caso, conviene desechar la denominación conjunciones coordinantes y quedarse con coordinantes a secas. A la postre, nada nuevo hay bajo el sol.

\section{Bibliografía}

Alarcos Llorach, Emilio (1994), Gramática de la lengua española, Madrid: Espasa Calpe.

Alcina Franch, Juan - Blecua, José Manuel (1975), Gramática española, Barcelona: Ariel.

ČERNÝ, Jiří (2000, 2008), Morfología española, Olomouc: Nakladatelství Univerzity Palackého.

Gómez Torrego, Leonardo (2007), Gramática didáctica del español, Madrid: Ediciones SM.

GonzÁlez CAlvo, José Manuel (2000b), «Sobre la palabra y las clases de palabras», en Revista Española de Lingüística (RSEL), 30, 2, 309-329.

GutiÉRREZ ORdóÑEZ, Salvador, «Sobre el sintagma preposicional, una vez más», en Cuartero Ortal, Juan - Emsel, Martina, VERNETZUNGEN. Bedeutung in Word, Satz und Text. Festschrift für Gerd Wotjak zum 65. Geburtstag, Band 1, Peter Lang, Frankfurt am Main, 2007, 209-219. 
Marcos MARín, Francisco et. al. (2002), Gramática española, Madrid: Editorial Síntesis. Pavón Lucero, $\mathrm{M}^{\mathrm{a}}$ Victoria (1999), «Clases de partículas: preposición, conjunción y adverbio», en BosQue, Ignacio - DemonTe, Violeta (coords.), Gramática descriptiva de la lengua española, Madrid: RAE (colección Nebrija y Bello)-Espasa Calpe.

RAE (1973), Esbozo de una nueva gramática de la lengua española, Madrid: Espasa-Calpe.

RAE - Aale (2010), Nueva gramática de la lengua española. Manual, Madrid: Espasa Libros, S. L.

Rodríguez Ramalle, Teresa María (2005), Manual de Sintaxis del Español, Madrid: Editorial Castalia.

José Manuel González Calvo Departamento de Filología Hispánica y Lingüística General

Facultad de Filosofía y Letras

Universidad de Extremadura

Campus Universitario

Avda. de la Universidad s/n

10071 Cáceres

España

jmgzalez@unex.es 